\title{
A study of health profile and effects of ambient air pollution among auto drivers of Bangalore city
}

Shwetha A Neralakatte ${ }^{1}$, Nanda Kumar Bidare Sastry ${ }^{2}$, Shivaraj Nallur Somanna ${ }^{3}$, Priyadarshini Chidambaram ${ }^{4}$

${ }^{1}$ Post Graduate, Department of Community Medicine, M S Ramaiah Medical College, Bangalore; ${ }^{2}$ Associate Professor, Department of Community Medicine, M S Ramaiah Medical College, Bangalore, Karnataka, India; ${ }^{3}$ Assistant Professor (Statistician), Department of Community Medicine, M S Ramaiah Medical College, Bangalore, Karnataka, India; ${ }^{4}$ Assistant Professor, Department of Community Medicine, M S Ramaiah Medical College, Bangalore, Karnataka, India

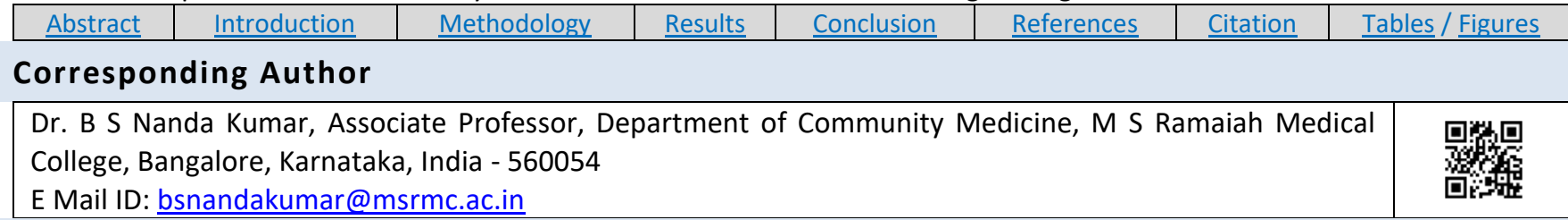

\section{Citation}

Neralakatte SA, Sastry NKB, Somanna SN, Chidambaram P. A study of health profile and effects of ambient air pollution among auto drivers of Bangalore city. Indian J Comm Health. 2021;33(3):491-496. https://doi.org/10.47203/IJCH.2021.v33i03.015

Source of Funding: Nil Conflict of Interest: None declared

\section{Article Cycle}

Received: 25/05/2021; Revision: 28/07/2021; Accepted: 17/08/2021; Published: 30/09/2021

This work is licensed under a Creative Commons Attribution 4.0 International License.

\section{Abstract}

Background: Auto drivers battle several occupational health hazards due to increasing pollution and unhealthy lifestyle. Improper diet and sleeping habits coupled with smoking, tobacco and alcohol use make them prone to respiratory and cardiovascular health hazards. Objectives: To assess the health status and quality of life (QoL) among auto drivers in Bangalore city and to study the association of selected parameters with respiratory and cardiac morbidities. Methods: In this cross-sectional study, 450 auto drivers were given a questionnaire and they were distributed according to age, education, body mass index, smoking, tobacco and/or alcohol consumption. The QoL was assessed by World Health Organization Quality of Life Instrument (WHOQOL-BREF) and peak expiratory flow, blood pressure, and blood sugar levels for each participant were recorded. The association between two categorical variables was determined by Chi-square test and $p \leq 0.05$ was considered statistically significant. Results: The association of number of years of driving with prevalence of chronic morbidity $(p=0.005)$, hypertension $(p=0.008)$, diabetes $(p<0.001)$, and heart disease $(p=0.04)$ were significant. QoL for physical and environmental domain were $16.11 \pm 0.28$ and $12.48 \pm 0.06$, respectively. Conclusion: A proportional increase in the risk of respiratory and cardiac morbidities with increasing number of driving years was observed among auto drivers.

\section{Keywords}

Diabetes Mellitus; Hypertension; Lifestyle; Occupational Health; Quality of life; Surveys and Questionnaires.

\section{Introduction}

Air pollution is a major environmental health problem affecting everyone (1). The main sources of air pollution are automobiles, industries, domestic sources like fuel and biomass burning, tobacco smoke, and other miscellaneous sources (2). The main components of air pollution are carbon monoxide, sulphur dioxide, lead, carbon dioxide hydrocarbons, cadmium, ozone, oxides of nitrogen, polycyclic hydrocarbons, etc. $(3,4)$. Particulate matter smaller than $2.5 \mathrm{MM}$ in diameter are dangerous as they may reach the peripheral regions of the bronchioles and interfere with the gas exchange in the lungs when inhaled (5).
Autorickshaws are preferred due to their compact size (6). The number of autos in Bangalore particularly has increased form 0.8 lacs in 2008 to 1.2 lacs in 2015. A study conducted in 2015 presented a mode share of $6.7 \%$ for cars and $10.4 \%$ for autos in Bangalore (7).

Auto drivers have several health hazards resulting in pneumonia, chronic obstructive pulmonary disease (COPD), lung cancer, and other complications like inflamed airway, tuberculosis (TB), nasopharyngeal cancer, and laryngeal cancer $(8,9)$.

The impact of pollution, nature of their profession, lack of facilities and access to healthcare on the health of auto drivers have not been elaborately explored. 


\section{Aim \& Objective}

To assess the health status, acute respiratory morbidities, and quality of life among auto drivers of Bangalore city.

\section{Material \& Methods}

Study design: The study was conducted over a period in an urban field practice area Bangalore city.

Inclusion and exclusion criteria: The study included 450 auto drivers operating in the vicinity of the study area, with a minimum driving period of 6 months and excluded those who were involved in ferrying general passengers (goods autos, school autos, etc., were excluded from the study).

Sample size calculation: The formula used for the calculation of sample size (10) was $\mathbf{4 P Q} / \mathbf{L}^{2}$, where,

$4=z \alpha$, indicating the standard normal deviate at a desired confidence level (95\% or $99 \%)$;

p, previous prevalence; $q, 100-p$;

L, allowable error, $5 \%, 10 \%$ or $20 \%$ of $p$ at $95 \%$ confidence level; $Z \alpha=1.96$.

Thus, sample size of 450 was obtained.

Study procedure: A pre-tested, semi-structured questionnaire with standardized health quality assessment tool was used. Quality of life was assessed using the World Health Organization Quality of Life Instrument (WHOQOL-BREF) which is an abbreviated version of WHOQOL-100 containing 4 domains and 26 facets (11). The steps followed for the assessment were in the following order:

1. Check all 26 items from assessment and have a range of 1-5

2. Reverse 3 negatively phrased items

3. Compute domain scores

4. Delete cases with $>20 \%$ missing data

5. Check domain scores and

6. Save data set [Supplementary Table S1]

Measuring blood pressure, blood sugar levels, height, weight, and Body Mass Index (BMI)

A mercury sphygmomanometer was used to measure blood pressure. The cut-off was taken as $\geq 140 \mathrm{~mm}$ of $\mathrm{Hg}$ and $\geq 90 \mathrm{~mm}$ of $\mathrm{Hg}$ for systolic and diastolic blood pressure respectively (12).

Glucometer was used for measuring the random blood sugar (RBS). Subjects with random plasma glucose levels $\geq 200 \mathrm{mg} / \mathrm{dL}$ were categorized as diabetic (13).

Height, weight, and BMI of each participant was measured as well. BMI $\left(\mathrm{kg} / \mathrm{m}^{2}\right)$ of each participant was calculated and subjects with $\mathrm{BMI}<18.5$ were considered underweight, 18.5-25 considered normal, 25-30 considered overweight, and a BMI of $>30$ was considered obese (14).

Peak expiratory flow (PEF) measurement: Standardized procedure was followed for the measurement of PEF. Participants were assigned to three zones - green, yellow, and red, according to the peak flow rates. The green zone represented an $80-100 \%$, yellow zone represented 50 -
$79 \%$, and the red zone represented $<50 \%$ of "normal" peak flow rates (15).

Ethical Approval: Approval from Institutional Ethics Committee (Reg no. SS-1/EC/13/2016) was acquired before the commencement of the study

Consent: Informed consent from the participants were acquired before the commencement of the study.

Data analysis: Data analysis was performed using statistical software R 4.0.3 and Excel. Continuous variables were represented as mean \pm standard deviation (SD) form and categorical variables by a frequency table. QQ plot/Shapiro-Wilk's test was used to check the normality of variables. Independent sample t-test / Mann-Whitney $U$ test was performed to compare the two groups. Chisquare test was used to determine the association between two categorical variables. $p \leq 0.05$ was set as statistically significant.

\section{Results}

The mean age of participants in the study was $40.55 \pm 8.96$ years. Majority of drivers belonged to age group 25-44 years $(n=284,63.11 \%)$ followed by $45-64$ years $(n=148$, $32.89 \%), \leq 24$ years $(n=16,3.56 \%)$ and $\geq 65$ years $(n=2$, $0.44 \%)$. Amongst the auto drivers, 190 (42.22\%) were smokers, 16 (3.55\%) and 73 (16.22\%) were ex- and current tobacco users respectively. With respect to alcohol consumption, 30 (6.66\%) and 171 (38.0\%) were reported to be ex- and current users. Only $36(8 \%)$ drivers had respiratory symptoms and $80(17.8 \%)$ had health insurance coverage. Baseline characteristics of the cohort are presented in [Table 1].

Self-reported quality of life score across the 4 domains of WHOQOL-BREF, physical health (domain 1), psychological (domain 2), social relationship (domain 3), and environmental (domain 4), were assessed. Physical domain had the highest self-reported quality of life score, $16.11 \pm 0.28$, while the environmental domain had the least, $12.49 \pm 0.06$.

Relationship between duration of driving and pathologies were studied and about $92 \%$ of the study participants did not report any respiratory symptoms. The association between years of driving and chronic morbidity was found to be significant $(p=0.005)$.

Hypertension was observed the least, 4.92\%, in participants with $<10$ years of driving as opposed to $25 \%$ in those with 31-40 years of driving. Hypertension was also found to be significantly associated with years of driving $(p=0.008)$.

Diabetes mellitus and heart diseases among auto drivers, were found to be significantly associated with years of driving ( $p<0.001$ and $p=0.04$ respectively). While diabetes was reported in $8.7 \%$ of those who had been driving for under 10 years, it was prevalent in $40 \%$ of those who had 31-40 years of driving.

Asthma was not significantly associated with number of years of driving $(p=0.52)$. The study showed a significant 
association between chronic morbidities, hypertension, diabetes mellitus, and heart diseases with number of years of driving $(p<0.05)$ with the risk of their incidence increasing with number of driving years [Table 2].

Association of PEF with smoking and WHOQOL-BREF scores: Among $42.22 \%$ of the participants who smoked, $52.63 \%$ of them were observed to have abnormal PEF. But this abnormal range was also observed in $55.77 \%$ of the participants who were non-smokers. There was no significant association observed between PEF and smoking $(p=0.57)$ [Table 3].

Effect of PEF on WHOQOL-BREF scores were also assessed and observed that there was no significant correlation among the two ( $p>0.05$ for each domain) with values for abnormal and normal PEF being almost the same in each domain [Table 4].

\section{Discussion}

As pollution increases steadily, exploring deteriorating health associated with occupational hazards in auto drivers is needed. To investigate this, the study assessed the health of 450 auto drivers constantly exposed to the impact of pollution and the grueling demands of the occupation. Age of the participants ranged from 18-69 years and $63.11 \%$ of the study group were between $25-44$ years. The study found that $39.11 \%$ and $21.11 \%$ of the auto drivers studied were overweight and obese, respectively. This prevalence of higher BMls among auto drivers could be due to the prolonged hours of sitting posture required by the profession. The results concur with a study done by Thiese et al (16), where $53.3 \%$ of truck drivers presented an increased likelihood of hypertension, diabetes, nervous disorders, sleep disorders, etc. This confirms that maintenance of $\mathrm{BMI}$ among auto drivers is crucial as it is an established risk factor for various diseases. The study shows that a little over half the study population, $51.56 \%$, had high school education and only $5.56 \%$ had a diploma or degree. This lower percentage of auto drivers with good education may have a bearing on their general understanding of risk factors of diseases and the preventive measures needed for the same.

About $42.22 \%$ of the participants were smokers and tobacco chewing were found among $16.22 \%$ of the study participants. This number is relatively higher than the general population. A study performed by Mahadik et al (17) found substance abuse among $59 \%$ of auto drivers in Navi Mumbai. In a similar study by Singhal et al (18) tobacco use was found in $64 \%$ of the auto drivers in Bareilly, Uttar Pradesh and $19 \%$ of them had oral sub mucous fibrosis, which is a precancerous lesion. When coupled with air pollution, the use of tobacco places auto drivers at a very high risk of respiratory morbidities. This holds true for consumption of alcohol as well which was found among $38 \%$ of the participants which is considerably high compared to the general population of men over 15 years of age (16.5\%, according to National Family Health Survey [NHFS] 5 data) (19). A prevalence of $43 \%$ for alcohol consumption among drivers in Kannur city was found in a study by Girish et al (20), putting them at a higher risk of developing cardiovascular diseases. Mean hours of driving per day was $10.14 \pm 1.92$. Long hours of work in pollution, untimely consumption of food and unhealthy habits like excessive smoking, tobacco use, and alcohol consumption cumulatively pose health hazards among auto drivers.

According to NHFS 5 data, $28.1 \%$ of the general population has insurance coverage (19). Only $17.8 \%$ of the participants had insurance coverage and a higher proportion of the study group, $84.44 \%$, earned an average of 10,000 rupees a month. The pressure of expenditure and economic stress could be one of the factors contributing to the reluctance among auto drivers to spend on healthcare services, which might impact their health and wellbeing. The new scheme of Ayushman Bharat may provide some relief with health facilities to auto drivers (21). Auto drivers' unions could promote group health insurance programs to overcome these economical barriers hindering their access to healthcare. The most common respiratory manifestations of pollution are cough, cold, and breathlessness. Continued exposure to polluted environment could predispose individuals to a plethora of ailments morbidity (22). In a study conducted by Sylla et al (23), 58\% of auto drivers had chronic cough, $65 \%$ had recurrent cold, $38 \%$ had asthma, and $30 \%$ had COPD. In a similar study by Stephen et al (24), 76\% of auto drivers in Puducherry had non-specific respiratory symptoms, 68\% among them had breathlessness, 22\% had cough, and $18 \%$ had wheezing.

Chronic morbidity was reported in $19.13 \%$ of the participants who had been driving for less than 10 years. This increased to $30.53 \%$ in those who had driven for 11 20 years, $37.5 \%$ in those with $21-30$ years of driving, and to $40 \%$ in those who had driven for $30-40$ years. This shows a trend of increasing prevalence of chronic morbidities among auto drivers with increasing number of years of driving $(p=0.005)$. The cumulative exposure to pollutants can also contribute to the dose gradient effect of chronic morbidity. A steady increase in hypertension among participants with 11-20 years and 21-30 years of driving as observed well. A significant association between number of years of driving and hypertension was established $(p=0.008)$ with a similar trend to that of chronic morbidity. The impact of years of driving on chronic morbidity and hypertension can be explained by the confounding effect of age as well. These results concur with a study done by Babu et al (25) in Kozhikode city which showed that $85 \%$ of auto drivers had chronic morbidity including hypertension. Another study by Borle et al (26) showed similar results where $34.8 \%$ of bus drivers had hypertension in Nagpur. Incidence of diabetes also increased steadily with number of driving years and 
were significantly associated with each other $(p<0.001)$.

Prevalence of heart diseases also followed the same pattern as chronic morbidity, hypertension, and diabetes. Heart diseases was not reported in any of the participants who had been driving for over 30 years but a rise in incidence was observed with increasing brackets of years of driving. Concurring with the pattern observed so far, heart disease was reported least $(0.55 \%)$ in participants with less than 10 years of driving compared to those with for 21-30 years of driving (5\%). Pathogenesis of diabetes and heart disease is related to stress, unhealthy eating habits, and long hours of sedentary work which is seen among auto drivers (27). Asthma did not follow the trend of increasing prevalence with increasing driving years but the compromised respiratory function among auto drivers was exhibited by abnormal PEF value, which was seen in $54.4 \%$ of the auto drivers. These results agree with several studies that have shown reduced PEF values among auto drivers $(28,29)$.

The mean scores of the participants studied across all domains are considerably low compared to published literature. This can be attributed to relatively lower quality of life index of auto drivers compared to the general population. Caution needs to be exercised while drawing conclusions as there are several cofounding factors affecting quality of life. Also, auto drivers are a part of the general adult population and the sub-fraction analysis may bring in bias.

\section{Conclusion}

Rising air pollution coupled with poor lifestyle practices such as smoking, use of alcohol/tobacco, unhealthy diet, have predisposed auto drivers at a great risk of developing chronic morbidities, diabetes mellitus, hypertension, and heart diseases. Association of deteriorating health with years of service among auto drivers in Bangalore city has been established in this study.

\section{Recommendation}

Despite the mentioned drawbacks, the study provides sufficient information to look at the association of morbidities to air pollutants owing to high levels of cumulative exposures. Auto drivers should be educated and trained regarding the ill effects of air pollution, smoking, chewing tobacco, and alcohol. They should be advised to wear mouth masks during driving hours and encouraged to attend regular health checks. Auto drivers to be counselled in a simple yet comprehensive manner regarding healthy lifestyle practices (importance of a balanced diet, exercise) along with the tell-tale signs of chronic pathologies to promote early diagnosis and intervention (30). Counselling would increase their awareness regarding morbidities and facilitate early diagnosis to improve the prognosis rates. Government and private organizations could work towards making health care affordable for autorickshaw drivers.

\section{Limitation of the study}

The main limitations of the study include the inability to extrapolate the findings to all auto drivers and an inherent bias in the information given by the participants, especially when it comes to habits. There may be inaccuracies in the information submitted by the participants and any inferential measures from environmental exposure have not be derived due to the bias associated with extrapolating ecological data to individual health outcomes.

\section{Relevance of the study}

This study provides information regarding the health status and quality of life among auto drivers. Occupational hazards coupled with environmental pollution leads to respiratory morbidities influencing the quality of life. The study highlights the need for evolving focused health care services and higher environmental monitoring.

\section{Authors Contribution}

Shwetha A N undertook this study as a part of her post graduate MD dissertation with B S Nanda Kumar as guide and Priyadarshini as Co-guide. Shivaraj NS provided the biostatistical support for conducting the study. All the authors were involved in preparing the manuscript and revising the same.

\section{Acknowledgement}

The authors wish to acknowledge the technical and administrative support from the faculty, Medico Social Workers and post graduates of Dept. of Community Medicine, Administrative heads of Ramaiah Medical College and Hospitals; Auto Drivers of Bangalore City who participated in the study.

\section{References}

1. Manisalidis I, Stavropoulou E, Stavropoulos A, Bezirtzoglou E. Environmental and health impacts of air pollution: a review. Front Public Health 2020;8:14.

2. Park K, Park's Textbook of Preventative and Social Medicine. 24th ed. Jabalpur: Bhanot Publishers; 2017.

3. Sierra-Vargas MP, Teran LM. Air pollution: impact and prevention. Respirology 2012;17(7):1031-8.

4. Mostofa MG, Rahman A, Ansary MM, Watanabe A, Fujita M, Tran LS Hydrogen sulfide modulates cadmium-induced physiological and biochemical responses to alleviate cadmium toxicity in rice. Sci Rep 2015;5:14078.

5. Xing YF, Xu YH, Shi MH, Lian YX. The impact of PM2.5 on the human respiratory system. J Thorac Dis 2016;8(1):E69-74.

6. Harding SE, Badami MG, Reynolds CC, Kandlikar M. Auto-rickshaws in indian cities: public perceptions and operational realities. Transp Policy $2016 ; 52: 143-52$.

7. Thakur P, Pal S. Estimating vehicular emissions from auto rickshaws plying in Bengaluru. Int J Sci Eng 2018;9(5):2241-5.

8. Debbarma D, Mitra S. Occupational health problems of the auto rickshaws service providers in Agartala city: a case study of nagerjala motor stand. Int J Cur Res Rev 2017;9(22):16.

9. Wong IC, Ng YK, Lui VW. Cancers of the lung, head and neck on the rise: perspectives on the genotoxicity of air pollution. Chin J Cancer 2014 ;33(10):476.

10. Singh SP, Misha SK, Chaudhary SS, Katyal R, Singh A, Joshi HS. Health status of auto-rickshaw drivers plying in Agra city. Med Pulse-Int Med J 2015;2(4):221-8. 
INDIAN JOURNAL OF COMMUNITY HEALTH / VOL 33 / ISSUE NO 03 / JUL-SEP 2021

11. Whoqol Group. Development of the World Health Organization WHOQOL-BREF quality of life assessment. Psychol Med 1998;28(3):5518.

12. Flack JM, Adekola B. Blood pressure and the new ACC/AHA hypertension guidelines. Trends Cardiovasc Med 2020;30(3):160-4.

13. American Diabetes Association. 2. Classification and Diagnosis of Diabetes. Diabetes Care 2017;40:S11-24.

14. Flegal KM, Kit BK, Graubard BI. Body mass index categories in observational studies of weight and risk of death. Am J Epidemiol 2014;180(3):288-96.

15. Adeniyi BO, Erhabor GE. The peak flow meter and its use in clinical practice. African J Respir Med 2011;6(2):5-8.

16. Thiese MS, Moffitt G, Hanowski RJ, Kales SN, Porter RJ, Hegmann KT. Commercial driver medical examinations: prevalence of obesity, comorbidities, and certification outcomes. J Occup Environ Med 2015;57(6):659.

17. Mahadik VJ, Waingankar P, Anjenaya S, Sanjeev S, Mali K. Crosssectional study of health status of auto rickshaw drivers in Vashi, Navi Mumbai, India. MGM J Med Sci 2019;4(4):164-70.

18. Singhal A, Agrawal P, Agrawal VK. Prevalence and determinants of tobacco use and oral sub mucous fibrosis in auto-rickshaw drivers at Bareilly, Uttar Pradesh, India. Int Surg J 2018;5(4):1449-53.

19. National Family Health Survey, India. Accessed January 31, 2021. Available from: http://rchiips.org/nfhs/NFHS5_FCTS/FactSheet_KA.pdf

20. Girish HO, Senan P, Koppad R, Venugopalan PP. Risk factors of cardiovascular diseases among autorickshaw drivers of Kannur, North Kerala: A Crosssectional Study. Int J Community Med Public Health 2016;3(12):3395-8.
[A study of health...] | Shwetha AN et al

21. National Health Authority. Ayushman Bharat. Updated January 15 2021. Accessed January 31, 2021. Available from https://pmjay.gov.in/resources/publication

22. Adhikari S, Gupta A. Respiratory symptoms among auto rickshaw drivers of Mangaluru. Int J Med Sci Public Health 2019 ;8(2):136-139.

23. Sylla FK, Faye A, Diaw M, Fall M, Tal-Dia A. Traffic air pollution and respiratory health: a cross-sectional study among bus drivers in Dakar (Senegal). Open J Epidemiol. 2018;8(01):81699.

24. Stephen $P$, Mahalakshmy T, Manju R, Laksham KB, Subramani S, Panda $\mathrm{K}$, et al. High prevalence of chronic respiratory symptoms among autorickshaw drivers of urban Puducherry, South India. Indian J Occup Environ Med 2018;22(1):40

25. Babu KS. Health risk of auto rickshaw drivers around silencer of heavy vehicles. IOSR J Environ Sci 2016;10(1):2319-99.

26. Borle AL, Jadhao A. Prevalence and associated factors of hypertension among occupational bus drivers in Nagpur City, Central India-A cross sectional study. Ntl J Community Med 2015;6:423-8.

27. Kolb H, Martin S. Environmental/lifestyle factors in the pathogenesis and prevention of Type 2 diabetes. BMC Med 2017;15(1):131.

28. Babu VK, Damodar KS. Effect of outdoor air pollution on pulmonary function of non smoking auto rickshaw drivers in Bangalore. Int J Clin Exp Physiol 2017;4(1):30-3.

29. Pramanik PU, Ganguli IN, Chowdhury AR, Ghosh BA. A study to assess the respiratory impairments among three-wheeler auto taxi drivers. Int J Life Sci Pharma Res 2013;3(1):94-9.

30. Dwivedi $M$, Pandey AR. Diabetes mellitus and its treatment: an overview. J Adv Pharmacol 2020;1(1):48-58.

\section{Tables}

\section{TABLE 1 BASELINE CHARACTERISTICS OF THE STUDY POPULATION}

\begin{tabular}{|c|c|c|}
\hline \multicolumn{2}{|r|}{ Mean (SD) } & \multirow{2}{*}{$\begin{array}{c}\text { Median (IQR) } \\
16(16,16)\end{array}$} \\
\hline Physical (domain 1) & $16.11(0.28)$ & \\
\hline Psychological (domain 2) & $14.02(0.1)$ & $14(14-14)$ \\
\hline Social (domain 3) & $14.67(0.06)$ & $14.67(14.67-14.67)$ \\
\hline Environmental (domain 4) & $12.49(0.06)$ & $12.5(12.5-12.5)$ \\
\hline Number of years of auto driving & $14.77(8.98)$ & $14(8-20)$ \\
\hline Hours of auto driving/day & $10.14(1.92)$ & $10(8-12)$ \\
\hline \multicolumn{2}{|c|}{ Variables } & No. of Participants (\%) \\
\hline \multirow[t]{6}{*}{ Education } & Not literate & $19(4.22)$ \\
\hline & Primary school & $34(7.56)$ \\
\hline & Middle school & $99(22)$ \\
\hline & High school & $232(51.56)$ \\
\hline & PUC & $41(9.11)$ \\
\hline & Degree/diploma/others & $25(5.56)$ \\
\hline \multirow[t]{4}{*}{ BMI Category } & Underweight & $10(2.22)$ \\
\hline & Normal weight & $169(37.56)$ \\
\hline & Overweight & $176(39.11)$ \\
\hline & Obese & $95(21.11)$ \\
\hline \multirow[t]{4}{*}{ Number of years of auto driving } & $<10$ & $183(40.67)$ \\
\hline & $11-20$ & $167(37.11)$ \\
\hline & $21-30$ & $80(17.78)$ \\
\hline & $>31$ & $20(4.44)$ \\
\hline \multirow[t]{3}{*}{ Hours of auto driving/day } & $<8$ & $119(26.44)$ \\
\hline & $9-10$ & $164(36.44)$ \\
\hline & $>11$ & $167(37.11)$ \\
\hline \multirow[t]{6}{*}{ Income per month in rupees } & 10,000 & $380(84.44)$ \\
\hline & 12,000 & $65(14.44)$ \\
\hline & 15,000 & $2(0.44)$ \\
\hline & 18,000 & $1(0.22)$ \\
\hline & 20,000 & $1(0.22)$ \\
\hline & 50,000 & $1(0.22)$ \\
\hline
\end{tabular}




\begin{tabular}{|c|c|c|c|c|c|c|}
\hline \multirow{3}{*}{ Morbidities } & \multirow{3}{*}{ Response } & \multicolumn{5}{|c|}{ No. of Participants (\%) } \\
\hline & & \multicolumn{4}{|c|}{ Driving duration (in years) } & \multirow[b]{2}{*}{ Total } \\
\hline & & $0-10$ & $11-20$ & $21-30$ & $31-40$ & \\
\hline \multirow[t]{3}{*}{ Chronic morbidities } & Yes & $35(19.13)$ & $51(30.54)$ & $30(37.5)$ & $8(40)$ & $124(27.55)$ \\
\hline & No & $148(80.87)$ & $116(69.46)$ & $50(62.5)$ & $12(60)$ & $326(72.44)$ \\
\hline & p-value & \multicolumn{4}{|c|}{$0.005^{*}$} & 450 \\
\hline \multirow[t]{3}{*}{ Hypertension } & Yes & $9(4.92)$ & $15(8.98)$ & $11(13.75)$ & $5(25.0)$ & $40(8.9)$ \\
\hline & No & $174(95.08)$ & $152(91.02)$ & $69(86.25)$ & $15(75.0)$ & $410(91.1)$ \\
\hline & p-value & \multicolumn{4}{|c|}{$0.008^{*}$} & 450 \\
\hline \multirow[t]{3}{*}{ Diabetes Mellitus } & Yes & $16(8.74)$ & $30(17.96)$ & $20(25)$ & $8(40)$ & $74(16.44)$ \\
\hline & No & $167(91.26)$ & $137(82.04)$ & $60(75)$ & $12(60)$ & $376(83.55)$ \\
\hline & p-value & \multicolumn{4}{|c|}{$<0.001^{*}$} & 450 \\
\hline \multirow[t]{3}{*}{ Heart diseases } & Yes & $1(0.55)$ & $1(0.55)$ & $4(5)$ & 0 & $6(1.33)$ \\
\hline & No & $182(99.45)$ & $166(99.40)$ & 76 (95) & $20(100)$ & 444 (98.66) \\
\hline & p-value & \multicolumn{4}{|c|}{$0.04 *$} & 450 \\
\hline \multirow[t]{3}{*}{ Asthma } & Yes & $2(1.09)$ & $5(2.99)$ & $1(1.25)$ & 0 & $8(1.77)$ \\
\hline & No & 181 (98.91) & 162 (97.01) & 79 (98.75) & $20(100)$ & 442 (98.22) \\
\hline & p-value & \multicolumn{4}{|c|}{0.52} & 450 \\
\hline
\end{tabular}

\section{TABLE 3 ASSOCIATION BETWEEN PEF AND SMOKING}

\begin{tabular}{|c|c|c|c|}
\hline Smoking & $\begin{array}{l}\text { PEF abnormal } \\
\text { Number (\%) }\end{array}$ & $\begin{array}{c}\text { Normal } \\
\text { Number (\%) }\end{array}$ & $p$-value \\
\hline Smokers & $100(52.63)$ & $90(47.37)$ & \multirow[t]{2}{*}{0.57} \\
\hline Non-smokers & $145(55.77)$ & $115(44.23)$ & \\
\hline Total & $245(54.4)$ & $205(45.5)$ & $450(100)$ \\
\hline
\end{tabular}

\section{TABLE 4 PEF AND QOL DOMAINS}

\begin{tabular}{|c|c|c|c|c|c|}
\hline \multirow[t]{2}{*}{ Domain } & \multicolumn{2}{|c|}{ PEF- abnormal } & \multicolumn{2}{|c|}{ PEF- normal } & \multirow[t]{2}{*}{ p-value } \\
\hline & Mean \pm SD & Median $\left(Q_{1}-Q_{3}\right)$ & Mean \pm SD & Median $\left(Q_{1}-Q_{3}\right)$ & \\
\hline Physical & $16.11 \pm 0.27$ & $16(16-16)$ & $16.12 \pm 0.3$ & $16(16-16)$ & 0.89 \\
\hline Psychological & $14.02 \pm 0.1$ & $14(14-14)$ & $14.02 \pm 0.1$ & $14(14-14)$ & 0.99 \\
\hline Social & $14.68 \pm 0.08$ & $14.67(14.67-14.67)$ & $14.67 \pm 0.0$ & $14.67(14.67-14.67)$ & 0.36 \\
\hline Environmental & $12.5 \pm 0.06$ & $12.5(12.5-12.5)$ & $12.5 \pm 0.05$ & $12.5(12.5-12.5)$ & 0.54 \\
\hline
\end{tabular}

